\title{
(อ) OPEN ACCESS \\ How to reach trustworthy decisions for caesarean sections on maternal request: a call for beneficial power
}

\author{
Kristiane T Eide, Kristine Bærøe
}

Department of Global Public Health and Primary Care, University of Bergen, Bergen, Hordaland, Norway

\section{Correspondence to} Dr Kristiane T Eide, Department of Global Public Health and Primary Care, University of Bergen, 5018 Bergen, Norway; kristiane.eide@uib.no

Received 14 January 2020 Revised 12 August 2020 Accepted 22 August 2020
Check for updates

(C) Author(s) (or their employer(s)) 2020. Re-use permitted under CC BY-NC. No commercial re-use. See rights and permissions. Published by BMJ.

To cite: Eide KT, Bærøe K. $J$ Med Ethics Epub ahead of print: [please include Day Month Year]. doi:10.1136/ medethics-2020-106071

\section{ABSTRACT}

Caesarean delivery is a common and life-saving intervention. However, it involves an overall increased risk for short-term and long-term complications for both mother and child compared with vaginal delivery. From a medical point of view, healthcare professionals should, therefore, not recommend caesarean sections without any anticipated medical benefit. Consequently, caesarean sections requested by women for maternal reasons can cause conflict between professional recommendations and maternal autonomy. How can we assure ethically justified decisions in the case of caesarean sections on maternal request in healthcare systems that also respect patients' autonomy and aspire for shared decisions? In the maternal-professional relationship, which can be characterised in terms of reciprocal obligations and rights, women may not be entitled to demand a Csection. Nevertheless, women have a right to respect for their deliberative capacity in the decision-making process. How should we deal with a situation of non-agreement between a woman and healthcare professional when the woman requests a caesarean section in the absence of obvious medical indications? In this paper, we illustrate how the maternal-professional relationship is embedded in a nexus of power, trust and risk that reinforces a structural inferiority for women. To accommodate for beneficial use of power, these decision processes need to be trustworthy. We propose a framework, inspired by Lukes' three-dimensional notion of power, which serves to facilitate trust and allows for beneficial power in shared processes of decision-making about the delivery mode for women requesting planned C-sections.

\section{BACKGROUND}

A caesarean section (CS) can be a life-saving intervention for both mother and child. While, in some parts of the world, lack of access to and underuse of CS may have devastating consequences, there is an emerging concern for the increasing use of CS conducted in the absence of obstetric indications. ${ }^{1}$ Worldwide, the CS rates increased from $12 \%$ in 2000 to $21 \%$ in $2015 .{ }^{1}$ The highest CS rates today are found in the Latin America and the Caribbean (44\%). Disparities are wide between and within countries. In China the rates range from $2 \%$ to $62 \%$ between provinces. ${ }^{1}$ Delivering by CS is associated with higher socioeconomic status in low-income and middle-income countries, ${ }^{1}$ while the opposite has been shown in a high-income country like Norway. ${ }^{2}$ In European studies, preference for CS, is associated with psychosocial vulnerability. ${ }^{3-5}$

WHO originally promoted a CS rate to be between $10 \%$ and $15 \%{ }^{6}$ Later, a worldwide study identified the lowest maternal and neonatal mortality to be associated with CS rates up to $19 \% .^{7}$ There are no available evidence from randomised control trials comparing outcomes of vaginal vs caesarean delivery for low-risk women lacking obstetric indication. ${ }^{8}$ Still, CS is in general associated with increased risk for short-term and long-term health complications for both mother and child, and are increasing with repeated caesareans. ${ }^{9}$ While the risk for short-term complications (including wound infections) are relatively low following planned caesarean delivery ${ }^{10-12}$ complications can occur in subsequent pregnancies such as abnormal placentation, uterine rupture, unexplained fetal death and postpartum haemorrhage. ${ }^{13-15}$ Consequently, decision-making, especially for first-time pregnancies, should involve consideration of future pregnancies and implications across the reproductive lifespan. For the newborns, planned CS may increase the risk for breastfeeding problems, respiratory distress ${ }^{16}$ and transfer to neonatal intensive care unit. ${ }^{17}$ In the long run, increasing evidence suggest that a planned caesarean delivery, affects the development of the child's immune system by providing a vulnerability for immune-mediated diseases such as asthma, allergies, diabetes mellitus (type 1) and coeliac disease. ${ }^{18-20}$

Along with the general rise in medically necessary caesarean deliveries, many countries have experienced a rise in women requesting planned CS in absence of obstetric indications. ${ }^{121}{ }^{22}$ Approximately $2.5 \%$ of births in the USA are suggested to be delivered as caesarean sections on maternal requests (CSMR). ${ }^{23}$ Scandinavian estimates suggest a prevalence of CSMR between $1 \%$ and $3 \%$ of births. ${ }^{21}{ }^{24-26}$ The reported willingness to comply with maternal requests and attitudes toward maternal autonomy vary among obstetricians across European countries. The lowest willingness is found in Spain and France, and highest willingness is within the UK and Germany. ${ }^{27}$ Maternal autonomy to choose a planned CS has been debated among professionals and ethicists, ${ }^{28-33}$ and guidelines vary between countries regarding how to handle these requests. ${ }^{3435}$

\section{Opposing autonomous claims and the call for shared decisions}

Respect for autonomy is one of the leading ethical principles of medical practice today. It is one out of the four equally important principles proposed by Beauchamp and Childress; respect for autonomy, beneficence, non-maleficence and justice. ${ }^{36}$ According to Pellegrino, benefiting 
patients implicitly includes respecting their capacity and wish for self-determination. ${ }^{37}$

Numerous interpretations and understandings of autonomy goes beyond the general notion of self-determination. ${ }^{38}$ In the much cited version proposed by Beauchamp and Childress, an autonomous decision must be intentional. The actor needs to have deliberated on the decision with a proper understanding of the relevant information and needs to be free from internal and external control (eg, mental health states, coercion and deception) ${ }^{3639}$. In medical practice, the usual interpretation of patient autonomy is that patients have a right to refuse offered treatment, but the patient may not have a right to choose treatment outside of the 'healthcare menu' as defined by the healthcare professionals and/or policy-makers. ${ }^{38}$ According to this view on patient autonomy, a woman cannot demand a planned CS unless a physician finds it medically indicated. According to Norwegian guidelines, for example, indications for CS are met when the anticipated benefit for the mother and child is higher with a CS compared with a vaginal delivery. ${ }^{35}$ Even if the woman does not hold a specific right to demand a treatment that is not medically indicated, she should still be respected for her ability to deliberate and take part in decisions in healthcare. But how should this capacity be respected when deliberation does not necessarily lead to consensus between the woman and the healthcare provider on the final decision?

The maternal-professional relationship constitutes a moral relationship of mutual (autonomous) rights as well as an obligation to respect each other. ${ }^{37}$ Even if she does not have the right to autonomously demand whatever she likes, the woman's ability to deliberate and reach conclusions should be respected. The necessity of her willing cooperation with professionals during a vaginal delivery-which can be mentally and physiologically challenging - adds to the importance of involving the woman in decision-making. Professionals hold a right to act in accordance with their professional integrity and make adequate medical decisions in line with their specialist knowledge and clinical judgement. ${ }^{37}$ An obstetrician, who is formally responsible for the consequences of the medical intervention, may thus object to operating on a woman who requests a CS against medical recommendations. Theoretically, this can be described as a situation of opposing autonomous claims. Practically, one party must give up its claim to make the decision. This means one party must be subjected to the will of the other, which involves lack of power to control the situation. On the individual level, this can create a damaging experience of powerlessness. On the societal level, this can create structures of power that support relative domination and subordination of either professionals or patients.

\section{Aim}

In the following, we discuss the nexus of power, trust and risk that surrounds the maternal-professional relationship. We argue that the decision-making process should be structured to facilitate trust and allow for beneficial power to exist rather than to focus on ideals about autonomous choices and shared decisionmaking. Leaning on Lukes' notion of power and an account for how it can be turned to serve beneficial purposes in healthcare, we justify a realistic rather than idealised conceptualisation of a shared decision-making process and propose a framework for ethically justified decision-making in the case of CSMR.

\section{Power, trust and risk}

In order to find conditions for an acceptable decision-making process and to promote healthcare personnel's power to do good, there is a need to broaden the context of analysis beyond the construction of autonomy. A useful perspective is proposed by Grimen. ${ }^{40}$ According to Grimen, the nature of the patientprofessional relationship lies in general within what he calls 'the nexus of power, trust and risk.' When someone reaches out for healthcare, that person's health is left in the custody of someone else (a professional) who is capable of taking care of it. This then transfers discretionary power over that person's health to a professional who possesses the special knowledge, judgement and discretionary space to provide care. By trusting the professional to provide beneficial help, that person also takes the risk of being provided with insufficient and/or harmful care. However, patients' options for help in a society where tasks are organised by division of labour are quite limited. According to Grimen, trust can occur voluntarily, or it can be forced due to the lack of alternative options. ${ }^{40}$ His conceptualisation of trust is thereby broader than definitions that exclude perceptions of trust as phenomena emerging from dependency. ${ }^{41} 42$ Overall, a patient's trust, or at least lack of mistrust, facilitates the professional's power base. ${ }^{40}$ Trust is risky and makes patients vulnerable to adverse consequences. When one trusts, according to Mark Warren, one gets benefits of cooperation in exchange for some risk for harm. ${ }^{43}$ Thus, trust allows power to do good to exist in healthcare and is crucial for healthcare to be provided. ${ }^{40}$

Power is used to provide benefits along with the ethical principle of doing good for patients in healthcare, but it can also be misused and cause harm. ${ }^{36}$ Overall, there is no reason to believe that professionals would want to misuse power in their daily work. Still, power has this potential, and doctors' professional autonomy, which represents quite some space for discretion and clinical judgement, creates a substantial space for any kind of power. According to Grimen, the power imbalance within the patient-professional relationship manifests itself in different ways: the gap in medical knowledge and skills between the parties, the lack of options for seeking adequate help elsewhere, and the issue of professionals' gatekeeping roles for protection of social goods. ${ }^{40}$ This leaves patients reaching out for help with a structural dependency on professionals, but this is also a dependency we might have to accept. We agree with Grimen's claim that radical changes to the nature of this relationship may not be sufficiently beneficial to patients. ${ }^{40}$ The alternative of leaving adequate medical education and care to everyone instead of a small group does not allow for specialisation and is not a sustainable approach.

\section{Power, trust and risk in the maternal-professional relationship}

Power can also foster trust through lack of options (forced trust), through delegated discretion by authorities, and through forecasted efficacy. ${ }^{44}$ Likewise, trust can be lost due to emergence of other options, such as complementary medicine and private healthcare. Due to dismissed legitimacy, for example, by representations of mixed motives such as providing care and saving public resources. Or due to perceived lack of efficacy caused by for example negative healthcare experiences and negative media publicity. ${ }^{44}$ The legitimate authority of professionals has been challenged in the last few decades due to increased access to medical knowledge among patients (e.g., via internet) as well as the establishment of patient rights and structural regulations of healthcare.

Public trust has been heavily challenged by the emergence of what Onora O'Neill describes as a culture of suspicion. ${ }^{45}$ She questions whether the evermore complex systems of accountability, in terms of requirements on reporting measurements, actually foster public trust. Proposals for how to reestablish or 
foster trust and power to do good in today's healthcare institutions include promotion of ethical quality and communication during the medical encounter. The ethics of meeting a patient as a whole person may replace paternalistic authority as a basis for trust. ${ }^{44}$ Introducing shared decision-making is an example of attempts to restore trust and thereby enable power to do good to exist in healthcare. Accepting division of labour in society and patients' structural dependency on medically educated others does not force us to completely reject such an idea. Rather, this prompts us to accept a conceptualisation of shared decisions that is in tune with real-world presences of the very same power and dependency. It is not our aim to discuss such a complete conceptualisation here, but we will argue below in favour of including dialogue in a practice-relevant concept as it relates to the case of CSMR.

\section{Towards a beneficial 'shared process of decision-making'}

Given the structural dependency of patients on professionals, it seams unrealistic to hold on to an ideal of shared decisionmaking assuming that both parties influence the conclusion of what to do with equal power. Moreover, 'shared process of decision-making' seems more realistic to aim for. This would especially be so when differences in the desired outcome are what bring the parties to negotiation in the first place. We will return to the implications of this below. Nevertheless, at this stage of analysis, there are several reasons for arguing that CSMR calls for equality in influencing the dialogue of the decision-making process. First, there are nuanced reasons and obstetric histories behind maternal caesarean requests. Such as previous birth and postnatal experiences, and perception of own risk and fear. ${ }^{47} 48$ Quality healthcare, therefore, calls for individual assessments and personalised, as opposed to standardised, recommendations. Morally, if clinical encounters between the woman and the professional regarding CSMR are to serve the best interests of the woman and child, both parties have the mutual obligation of facilitating an open and honest dialogue. The woman must reveal her reasons for the presumed benefit of the intervention. The professional should provide accurate information and a well-justified medical recommendation. If a woman does not provide any beneficial reason for her CS request, an obstetrician has strong reasons to object to operating in complete lack of expected benefit. ${ }^{37}$ If the level of evidence is weak regarding the safest delivery mode, the recommendation should reflect this.

Second, the subjective perspective of the woman is clinically relevant. CS represents a surgical interference on a physiological process the female body is made to handle and leads to an elevated risk. Therefore, vaginal delivery is recommended in a low-risk pregnancy. ${ }^{9}$ However, an unwilling vaginal delivery increases the risk of post-traumatic stress and depression among women. ${ }^{40}$ Experience of coercion may provide more future harm than benefit for the woman and her child. Individual evaluation of the risks and benefits of planned CS should also include prospective physical and mental health for the mother and child. It is not necessarily true that professionals hold a better capacity to judge future mental health prospects than the woman herself does. This calls for dialogue.

Fostering dialogue is necessary, but it is not enough to make the notion of a shared process of decision-making both realistic and ethically acceptable in case of CSMR. To see what more is called for (again inspired by Grimen ${ }^{40}$ ), we will apply Lukes' account $^{51}$ of power to explore and identify requirements for promoting beneficial power. We hereafter conceptualise 'beneficial power' as a form of power that is applied by healthcare professionals to promote patient treatment without suppressing patients' experiences or points of view.

\section{Three dimensions of power and shared process of decision- making}

According to Lukes' original framework of power, power can be realised through three dimensions. ${ }^{51}$ The first dimension refers to coercion (including physical force) where A coerces B to do something. The second dimension of power occurs when $\mathrm{A}$ is controlling the agenda for the interaction with $\mathrm{B}$. In medical encounters, professionals present information and options as well as define the needs for follow-ups. Hence, they hold considerable power over the terms for the encounters, that is, what is to be revealed to and considered by patients. The third dimension of power entails that A controls B's view on the world and how her situation is defined (eg, as illness/not-illness or as normal/abnormal).

For women who are requesting CS in absence of obstetric reasons, their perspective on what would be best for them often originates outside of or prior to the clinical encounter. However, when trust exists, professionals enjoy the beneficial power (and possess an obligation) to deliver honest information through counselling and avoid misconceptions about safety among women. ${ }^{52}$ Denying a woman the option of a planned CS when she insists on a self-perceived need after an informed process illustrates the power obstetricians hold over defining her need. This is based on a conceptualisation of medical indication and control over treatment options. Moreover, professionals set the agenda of interaction, controlling the process of decision-making by determining the time, schedule and aims of the meetings. Finally, they can indirectly coerce women into vaginal delivery. In Norway obstetricians have the final say about delivery mode. ${ }^{35}$ In the UK, physicians are expected to comply with persistent requests after counselling or refer the woman to another provider in the case of objection. ${ }^{34}$ Hence, patient choices and informed consent in maternal care can be influenced by agenda setting, worldview control and even coercion. Obstetricians hold both the power to control the content and scope of the dialogue and the right to refuse to provide CSMR. This increases vulnerability in her situation and may increase her perception of risk involved in trusting professionals and their decision about delivery mode. In the following section, we suggest structural initiatives to facilitate trust and enable beneficial power in the counselling process for caesarean requests.

\section{How to facilitate trust and beneficial power in decisions about CSMR: a framework}

Based on our discussion, we here suggest a decision making framework that promotes trustworthy beneficial power, that is, power without suppressing features. The framework consists of seven requirements, which all have to be present in order for decision-making power of healthcare personnel to be truly trustworthy.

\section{First criterion}

Deciding on delivery mode when the woman requests a CS requires a shared decision-making process to avoid harm. Equal respect between both parties requires reciprocity regarding the exchange of information. This means that the healthcare worker must knowledgably inform the woman about the intervention, and the woman must expose her reasons for requesting a CS. 


\section{Second criterion}

The mere possibility of being forced into a feared vaginal delivery should be off the table when the aim is to foster a trustworthy and beneficial decision-making process without suppressing coercion. The dialogue must be carried out without any agenda of pressuring the woman to opt for vaginal delivery. It must also avoid convincing her that, at the end of the day, she will not have or is unlikely to have a planned CS. Allowing for appeal for a second opinion if the dialogue does not bring about consensus is a way to promote this.

\section{Third criterion}

The third criterion relates to Lukes' second dimension of the concept of power, that is, the ability A has to control the agenda for interaction with B. For the dialogue to be beneficial, it should take place on the premises agreed on by both parties. This means that the woman should be involved in the planning of future meetings with respect to time issues, whom to meet, and what to discuss. Some women may prefer to meet with an obstetrician while others may prefer counselling led by a midwife. Psychologically trained teams would be beneficial. Standardised protocols for these meetings and conversations could undermine the beneficial power healthcare workers might exercise toward these women.

\section{Fourth criterion}

Lukes' third dimension of power concerns A's ability to control B's view of the world as well as how the situation is described. Any authoritative use of technical medical terms, such as claims on 'normal' delivery modes or 'right' and 'wrong' procedures, by the healthcare worker does not support the use of beneficial power and should be avoided. To avoid controlling the perspective of the situation at hand, the healthcare worker should also be open about risk factors concerning the individual. Furthermore, the probability of complications should be communicated along with the certainty of evidence.

\section{Fifth criterion}

In order to ensure that all women receive the same neutrally conveyed information without any undue influence of the world view of the professional, an information sheet should be made available for them and for the public. This requirement allows for critical assessment and debate about presented interpretations of research regarding risks and benefits of planned delivery modes.

\section{Sixth criterion}

To support and foster beneficial power of care providers, a professional endorsement of use of beneficial power should be reflected in healthcare education programmes and codes of ethics.

\section{Seventh criterion}

To institutionalise the trustworthiness of professionals' aim to use their power to do good, involves holding them accountable for their use of power. Regulatory mechanisms ensuring that requirements 1-6 are in place as well as a possibility for appeals by women who have experienced suppressing power abuse are both needed.

Lack of trust inhibits communication and cooperation. Both are vital for counselling and delivery care. ${ }^{41}$ If this framework is implemented to accommodate ethically justified use of power in decision-making about delivery mode, then women have reasons to trust professionals' motives, information and recommendations throughout the counselling process. If trust is ensured, benefits can emerge from the asymmetric power relations and serve the interest of women and their children.

\section{CONCLUSION}

In this paper, we have shown how women are placed in a situation of structural inferiority in the maternal-professional relationship when requesting a planned CS for maternal reasons. Although she may not be entitled to demand a planned CS, she should be included in decision-making processes about delivery mode. We have used Lukes' account of power to illustrate a need for structural initiatives that women can find trustworthy. This may allow beneficial power to exist in these consultations and we have proposed a framework to implement these initiatives. The normative premises for this particular framework, that is, the call for promotion of power that is beneficial for patients, might be relevant for framing other ethically challenging decisionmaking processes as well.

Acknowledgements KTE would like to give a special thanks to the Ethox Centre at the University of Oxford for a fruitful stay as a visiting student, providing ideas for the early drafts of this paper. Also great thanks to the Global Health Priorities research group at the University of Bergen for valuable discussions and feedback on the paper.

Contributors Both authors discussed and developed this paper from idea to draft. Both contributed to and approved the final draft.

Funding KTE was funded by the University of Bergen with a PhD scholarship, no grant/award number.

Competing interests None declared.

Patient consent for publication Not required.

Provenance and peer review Not commissioned; externally peer reviewed.

Data availability statement There are no data in this work.

Open access This is an open access article distributed in accordance with the Creative Commons Attribution Non Commercial (CC BY-NC 4.0) license, which permits others to distribute, remix, adapt, build upon this work non-commercially, and license their derivative works on different terms, provided the original work is properly cited, appropriate credit is given, any changes made indicated, and the use is non-commercial. See: http://creativecommons.org/licenses/by-nc/4.0/.

\section{REFERENCES}

1 Boerma T, Ronsmans C, Melesse DY, et al. Global epidemiology of use of and disparities in caesarean sections. Lancet 2018;392(10155):1341-8.

2 Tollånes MC, Thompson JMD, Daltveit AK, et al. Cesarean section and maternal education; secular trends in Norway, 1967-2004. Acta Obstet Gynecol Scand 2007;86(7):840-8.

3 Ryding EL, Lukasse $M$, Kristjansdottir $\mathrm{H}$, et al. Pregnant women's preference for cesarean section and subsequent mode of birth - a six-country cohort study. J Psychosom Obstet Gynaecol 2016;37(3):75-83.

4 Sydsjö G, Möller L, Lilliecreutz C, et al. Psychiatric illness in women requesting caesarean section. BJOG 2015;122(3):351-8.

5 Fuglenes $D$, Aas $E$, Botten $G$, et al. Why do some pregnant women prefer cesarean? the influence of parity, delivery experiences, and fear. Am J Obstet Gynecol 2011;205(1):45.e1-45.e9.

6 World Health Organization (WHO). Statement on caesarean section rates. World Health organization, 2015. Available: http://apps.who.int/iris/bitstream/handle/10665/ 161442/WHO_RHR_15.02_eng.pdf;jsessionid=F28E7A37F93A987CBDFA9446 8A69D3C5? sequence $=1$ [Accessed 10 Jan 2019].

7 Molina G, Weiser TG, Lipsitz SR, et al. Relationship between cesarean delivery rate and maternal and neonatal mortality. JAMA 2015;314(21):2263-70.

8 Lavender T, Hofmeyr GJ, Neilson JP, et al. Caesarean section for non-medical reasons at term. Cochrane Database Syst Rev 2012;3:CD004660.

9 Sandall J, Tribe RM, Avery L, et al. Short-Term and long-term effects of caesarean section on the health of women and children. Lancet 2018;392(10155):1349-57.

10 Otkjaer AM, Jørgensen HL, Clausen TD, et al. Maternal short-term complications after planned cesarean delivery without medical indication: a registry-based study. Acta Obstet Gyneco/ Scand 2019;98(7):905-12.

11 Wax JR. Maternal Request cesarean versus planned spontaneous vaginal delivery: maternal morbidity and short term outcomes. Semin Perinatol 2006:30(5):247-52.

12 Liu X, Landon MB, Cheng W, et al. Cesarean delivery on maternal Request in China: what are the risks and benefits? Am J Obstet Gynecol 2015;212(6):817.e1-9. 
13 Gilliam M. Cesarean delivery on Request: reproductive consequences. Semin Perinatol 2006;30(5):257-60

14 Lee YM, D'Alton ME. Cesarean delivery on maternal Request: maternal and neonatal complications. Curr Opin Obstet Gynecol 2008;20(6):1-601.

15 Colmorn LB, Krebs L, Klungsøyr K, et al. Mode of first delivery and severe maternal complications in the subsequent pregnancy. Acta Obstet Gynecol Scand 2017:96(9):1053-62.

16 Karlström A, Lindgren $\mathrm{H}$, Hildingsson I. Maternal and infant outcome after caesarean section without recorded medical indication: findings from a Swedish case-control study. BJOG 2013;120(4):479-86. discussion 486.

17 Kolås T, Saugstad OD, Daltveit AK, et al. Planned cesarean versus planned vaginal delivery at term: comparison of newborn infant outcomes. Am J Obstet Gynecol 2006;195(6):1538-43.

18 Cho CE, Norman M. Cesarean section and development of the immune system in the offspring. Am J Obstet Gynecol 2013;208(4):249-54.

19 Sevelsted A, Stokholm J, Bønnelykke K, et al. Cesarean section and chronic immune disorders. Pediatrics 2015;135(1):e92-8.

20 Mårild K, Stephansson 0, Montgomery S, et al. Pregnancy outcome and risk of celiac disease in offspring: a nationwide case-control study. Gastroenterology 2012;142(1):39-45.

21 Karlström A, Rådestad I, Eriksson C, et al. Cesarean section without medical reason, 1997 to 2006: a Swedish register study. Birth 2010;37(1):11-20.

22 MacKenzie IZ, Cooke I, Annan B. Indications for caesarean section in a consultant obstetric unit over three decades. J Obstet Gynaecol 2003;23(3):233-8.

23 American College of Obstetricians and Gynecologists. ACOG Committee opinion no. 559: cesarean delivery on maternal Request. Obstet Gynecol 2013;121(4):904-7.

24 Forstholm MM. Lidegaard 0: [Cesarean section on maternal request]. Ugeskr Laeger 2009;171(7):497-502.

25 Kolås T, Hofoss D, Daltveit AK, et al. Indications for cesarean deliveries in Norway. Am J Obstet Gynecol 2003;188(4):864-70.

26 Fuglenes $\mathrm{D}$, Aas $\mathrm{E}$, Botten $\mathrm{G}$, et al. Maternal preference for cesarean delivery: do women get what they want? Obstet Gynecol 2012;120(2 Pt 1):252-60.

27 Habiba M, Kaminski M, Da Frè M, et al. Caesarean section on Request: a comparison of obstetricians' attitudes in eight European countries. BJOG 2006;113(6):647-56.

28 Chervenak F, McCullough LB. For: responding professionally to requests for nonindicated caesarean delivery. BJOG 2015;122(3).

29 Silver RM. Against: caesarean delivery on maternal Request is a bad idea. BJOG 2015;122(3).

30 Gee H. Caesarean section should be available on Request: for: the mother's autonomy should be paramount. BJOG 2015;122(3).

31 Easter A. Against: women need accessible evidence-based information on caesarean section. BJOG 2015;122(3):359-60.

32 Chervenak FA. McCullough lb: ethical issues in cesarean delivery. Best Pract Res Clin Obstet Gynaecol 2017;43:68-75.

33 Chervenak FA, McCullough LB. The professional responsibility model of obstetric ethics and caesarean delivery. Best Pract Res Clin Obstet Gynaecol $2013 ; 27(2): 153-64$
34 National Institute for Health and Care Excellence (NICE). Caesarean section. National Institute for health and care excellence, 2011. Available: https://www.nice.org.uk/ guidance/cg132 [Accessed 14 Feb 2019].

35 Norsk Gynekologisk Forening (Norwegian Society for Gynecology and Obstetrics): Veileder i fødselshjelp. Chapter 40: C-section. In: Norwegian Society for gynecology and obstetrics): Veileder I fødselshjelp. Kapittel 40: Keisersnitt (guideline in obstetric care). Norsk Gynekologisk Forening (Norwegian Society for Gynecology and Obstetrics), 2014. http://legeforeningen.no/Fagmed/Norsk-gynekologisk-forening/ Veiledere/Veileder-i-fodselshjelp-2014/Keisersnitt/

36 Beauchamp TL. Childress JF: principles of biomedical ethics. 7th edn. New York: Oxford University Press, 2013.

37 Pellegrino ED. Patient and physician autonomy: conflicting rights and obligations in the physician-patient relationship. J Contemp Health Law Policy 1994:10:47-68.

38 O'Neill O. Autonomy and trust in bioethics. Cambrige, New York: Cambrige University Press, 2002.

39 Dive L, Newson AJ. Reconceptualizing autonomy for bioethics. Kennedy Inst Ethics J 2018;28(2):171-203

40 Grimen H. Power, trust, and risk: some reflections on an absent issue. Med Anthropol Q 2009;23(1):16-33.

41 Ozawa S. The role of trust in health care settings: does trust matter? Oxford Policy Institute, 2008

42 Gilson L. Trust and the development of health care as a social institution. Soc Sci Med 2003;56(7):1453-68

43 Warren M. Democracy \& trust. Cambridge: Cambridge University Press, 1999

44 Grimen H. [Trust and power--three interrelationships]. Tidsskr Nor Laegeforen 2001;121(30):3617-9.

45 O’Neill O. A question of trust. Cambridge University Press, 2002.

46 Clayman ML, Gulbrandsen P, Morris MA. A patient in the clinic; a person in the world. Why shared decision making needs to center on the person rather than the medical encounter. Patient Educ Couns 2017;100(3):600-4.

47 Eide KT, Morken N-H, Bærøe K. Maternal reasons for requesting planned cesarean section in Norway: a qualitative study. BMC Pregnancy Childbirth 2019;19(1):102.

48 O'Donovan C, O'Donovan J. Why do women Request an elective cesarean delivery for non-medical reasons? A systematic review of the qualitative literature. Birth 2018;45(2):109-19.

49 Garthus-Niegel S, von Soest T, Knoph C, et al. The influence of women's preferences and actual mode of delivery on post-traumatic stress symptoms following childbirth: a population-based, longitudinal study. BMC Pregnancy Childbirth 2014;14:191.

50 Olieman RM, Siemonsma F, Bartens MA, et al. The effect of an elective cesarean section on maternal Request on peripartum anxiety and depression in women with childbirth fear: a systematic review. BMC Pregnancy Childbirth 2017;17(1):195

51 Lukes S. Power: a radical view. Blackwell: Oxford, 1974

52 Burrow S. On the cutting edge: ethical responsiveness to cesarean rates. Am J Bioeth 2012:12(7):44-52 